\title{
Clinical relevance and implications of antenatal hydronephrosis
}

\author{
J A Dudley, J M Haworth, M E McGraw, J D Frank, E J Tizard
}

\begin{abstract}
Detailed antenatal sonography was performed on 18766 pregnant women between 1990 and 1994. Antenatal hydronephrosis, defined as an antero-posterior diameter of the renal pelvis (APPD) greater than $5 \mathrm{~mm}$, was detected in 100 cases $(0.59 \%)$. Sixty four infants had postnatal hydronephrosis at one and/or six weeks after delivery; 21 of these had urological anomalies.

Twelve infants had vesico-ureteric reflux. In all refluxing units the APPD of the renal pelvis was less than $10 \mathrm{~mm}$. Three patients had obstruction at the pelviureteric junction (PUJ); all required surgery.

Vesico-ureteric reflux is emerging as the most common urological finding in infants with antenatal hydronephrosis and is likely to be missed if kidneys with APPD of less than $10 \mathrm{~mm}$ are not further investigated. In contrast, pelvi-ureteric junction obstruction may be overdiagnosed, based only on drainage patterns of dynamic renogram studies.

(Arch Dis Child 1997;76:F31-F34)
\end{abstract}

Keywords: antenatal hydronephrosis; urinary tract; antero-posterior diameter of the renal pelvis.

Abnormalities of the urinary tract are reported to account for $30-50 \%$ of fetal anomalies. ${ }^{1-4}$ The presence of hydronephrosis at any stage of gestation is generally the first indicator of a potential urinary tract anomaly. There is, however, no agreed definition of "significant" antenatal hydronephrosis that warrants further investigation and no consensus on appropriate management. We followed up prospectively 100 neonates with antenatally diagnosed hydronephrosis and recommend management guidelines on the basis of our findings.

Department of Paediatric Nephrology, Southmead Hospital, Westbury on Trym, Bristol

JA Dudley

ME McGraw

EJ Tizard

Department of

Urology

JD Frank

Department of

Radiology

JM Haworth

Correspondence to: Dr JA Dudley.

Accepted 22 October 1996 Methods lysed retrospectively. Detailed antenatal sonography was performed on 18766 women attending antenatal clinics in Southmead Hospital, Bristol, between February 1990 and February 1994 . The first ultrasound scan was performed at between 14 and 18 weeks of gestation. Serial scans were performed at six weekly intervals in those cases where there was evidence of dilatation of the renal pelvis (APPD $>5 \mathrm{~mm}$ ). Postnatally, all infants with antenatal hydronephrosis were given prophy- lactic trimethoprim $2 \mathrm{mg} / \mathrm{kg} /$ day. A renal ultrasound scan was subsequently performed in the first week of life and again at 6 weeks of age. In cases where there was no evidence of postnatal hydronephrosis on either scan, no further investigations were undertaken apart from repeat ultrasound scans at 12 months. If hydronephrosis was confirmed further scans were performed at 3, 12, and 24 months. Micturating cystourethrography (MCUG) was performed in patients who had evidence of postnatal hydronephrosis at 1 and/or 6 weeks postnatally.

99m Tc-labelled dimercaptosuccinic acid (DMSA) scans were undertaken where there was evidence of vesico-ureteric reflux (VUR) or suspected multicystic dysplastic kidney.

99m Tc-labelled mercapto-acetyl triglycine (MAG 3) renograms were performed where hydronephrosis persisted in the absence of vesico-ureteric reflux, or if there was suspicion of obstruction on postnatal ultrasound (APPD $>10 \mathrm{~mm}$ ).

\section{Results}

One hundred infants with antenatal hydronephrosis were identified ( $M: F$ ratio $1.86: 1$ ), an incidence of $0.59 \%$. Gestational age at first abnormal scan was recorded in 89 cases; mean gestational age was 25 weeks (14-39 weeks). During the period of study, three pregnancies were terminated because of renal abnormalities and a further three pregnancies were terminated where renal anomalies were part of a malformation syndrome. There were no attempts at decompression of the fetal urinary tract. Hydronephrosis was bilateral in 46 , left sided in 28, right sided in 11 and unspecified in 15 fetuses. In 46 cases the abnormality was not detected until the third trimester; the "anomaly scan" at the time of booking had been normal. Resolution of the hydronephrosis before delivery was seen in 15 cases. However, postnatal hydronephrosis was shown in seven of these infants, two of whom had high grade vesicoureteric reflux and one of whom had a duplex system (table 1 ).

All 100 infants were followed up for between 
Table 1 Final diagnosis and outcome

\begin{tabular}{|c|c|c|c|}
\hline Condition & $\begin{array}{l}\text { No of } \\
\text { patients }\end{array}$ & $\begin{array}{l}\text { Gestational age at } \\
\text { first abnormal } \\
\text { ultrasound scan }\end{array}$ & Outcome \\
\hline \multicolumn{4}{|l|}{ VUR: } \\
\hline Isolated & 6 & $\begin{array}{l}18,18,34,31, \\
20,26\end{array}$ & Normal renal function \\
\hline $\begin{array}{l}\text { With contralateral multicystic } \\
\text { dysplastic kidney }\end{array}$ & 2 & 28,38 & $\begin{array}{l}\text { Normal renal function in } \\
\text { refluxing kidney }\end{array}$ \\
\hline With hypoplasia & 1 & 18 & \\
\hline With duplex system & 1 & 16 & \\
\hline $\begin{array}{l}\text { With duplex system and } \\
\text { hypoplasia }\end{array}$ & 2 & 17, NA & \\
\hline PUJ obstruction & 3 & 12, NA, 20 & $\begin{array}{l}\text { Nephrectomy (2), } \\
\text { pyeloplasty (1) }\end{array}$ \\
\hline Duplex - isolated & 1 & 18 & Equal renal function \\
\hline $\begin{array}{l}\text { Multicystic dysplastic kidney - } \\
\text { isolated }\end{array}$ & 2 & 18,37 & $\begin{array}{l}\text { Normal renal function in } \\
\text { contralateral kidneys }\end{array}$ \\
\hline Non-obstructive megaureter & 3 & $34,34, \mathrm{NA}$ & $\begin{array}{l}\text { Symmetrical function, } \\
\text { improved drainage (2) }\end{array}$ \\
\hline Total & 21 & & \\
\hline
\end{tabular}

$\mathrm{NA}=$ not available.
Table 3 Grade of hydronephrosis in infants with obstructive uropathy and VUR

\begin{tabular}{lll}
\hline Grade of hydronephrosis & VUR & PUf obstruction \\
\hline 0 & 3 & \\
1 & 13 & \\
2 & 2 & 1 \\
3 & & 2 \\
4 & 18 & 3 \\
Total & 18 \\
\hline
\end{tabular}

for bilateral obstruction; pyeloplasty alone in the third infant). In all three kidneys with PUJ obstruction the diameter of the renal pelvis was greater than $15 \mathrm{~mm}$ (table 3). Two other patients had clinically relevant hydronephrosis, one of whom had reduced drainage on MAG 3 renography; both have been monitored with serial ultrasonography and renography. At the time of writing, neither has evidence of deteriorating renal function, and hydronephrosis is resolving in both cases at 2 and 4 years of age.

Three patients had non-obstructive megaureter; all have been managed conservatively with serial renography and ultrasonography. All have equal renal function.

Of the 43 patients with postnatal hydronephrosis in whom no abnormality could be shown, in 20 hydronephrosis had completely resolved at 12 months, 14 have persistent hydronephrosis and nine have declined further investigation.

\section{Discussion}

Abnormalities of the urinary tract are reported to occur in $0.1-0.92 \%$ of pregnancies. ${ }^{6-9}$ This discrepancy in incidence relates partly to the timing of the antenatal ultrasound scan. Accurate visualisation of the pelvicalyceal system and renal parenchyma may not be possible before 18-20 weeks of gestation. In a prospective screening programme for fetal abnormalities in Sweden only 9\% of renal abnormalities were detected before 17 weeks of gestation, while $91 \%$ were detected by 33 weeks. ${ }^{1}$ If a second ultrasound scan were to be performed in all pregnancies at 30 to 36 weeks, it is likely that reported incidence rates of hydronephrosis and vesico-ureteric reflux would be higher. Our results are consistent with this; in 46 women the hydronephrosis was an incidental finding on sonography performed for nonnephrological reasons after 28 weeks of gestation.

Another explanation for the variation in incidence rates is the terminology used to define hydronephrosis. Grignon ${ }^{10}$ concluded that an APPD < $10 \mathrm{~mm}$ should be regarded as physiological as in his series of patients 28 of 29 cases with an APPD $<10 \mathrm{~mm}$ showed complete resolution of the hydronephrosis either before delivery or in the first year of life. Similar findings have been reported in subsequent studies. ${ }^{11}{ }^{12}$ However, much of this work relates to evaluation of potential obstructive uropathy and it is conceivable that some infants with vesico-ureteric reflux will have been missed. Predictably, as those cases of mild (APPD < $10 \mathrm{~mm}$ ) hydronephrosis are more extensively investigated, so the relative 
contribution of vesico-ureteric reflux to the spectrum of pathology is increasing. ${ }^{13-15}$

Twelve patients (19\% of those with postnatal hydronephrosis) in our series had evidence of vesico-ureteric reflux. However, as 16 of 64 patients with postnatal hydronephrosis did not have cystography performed, the actual number of infants with vesico-ureteric reflux is likely to be higher than this. The frequency of detection of vesico-ureteric reflux in infants with mild hydronephrosis has been reported to be $20 \%$ in a previous series. ${ }^{15}$ It is becoming apparent that vesico-ureteric reflux may be associated with normal ante- and postnatal ultrasound scans. There are several reports of spontaneous resolution of fetal and neonatal upper urinary tract dilatation. ${ }^{16-18}$ There are similar reports of spontaneous cessation of vesico-ureteric reflux without renal damage ${ }^{19-22}$; it may be that as we investigate "mild" antenatal hydronephrosis, we are identifying greater numbers of infants with transient vesico-ureteric reflux which may be of no importance. Historically, the assumption has been made that renal scarring is a result of infection in refluxing units. However, many authors have identified focal and global parenchymal defects in "infection-free" renal units $^{23-25}$ Other reports have clearly shown parenchymal defects in the absence of reflux. It is quite conceivable that many cases of renal scarring reflect pre-existing limitations of renal capacity rather than independent infections in refluxing kidneys. In such cases early diagnosis and institution of antibiotic prophylaxis may not be beneficial. We are aiming to embark on a formal prospective trial into the benefits of antibiotic prophylaxis in infants with antenatal hydronephrosis. Until information from such a trial becomes available, with the knowledge that vesico-ureteric reflux is common in cases of mild antenatal hydronethrosis, we propose that micturating cystourethrography should be performed on all cases of antenatal hydronephrosis that are confirmed postnatally. Immediate prophylaxis should be started in these infants; this may be discontinued if vesico-ureteric reflux is not confirmed on micturating cystourethrographyraphy. We perform a DMSA scan within the first few months of life in those infants known to have reflux: to date we have identified generalised hypoplasia but no evidence of scarring.

Our rate of PUJ obstruction is less than that reported in other series. ${ }^{26}{ }^{27}$ This may reflect differences in terminology and interpretation of dynamic renogram studies. There has been considerable debate about indications and timing of surgery for PUJ obstruction. ${ }^{28-30}$ The ultimate aim in these cases has to be preservation of renal function; proponents of early surgery would claim that pyeloplasty should be performed before function is allowed to deteriorate. Ransley et $a \beta^{11}$ monitored 23 patients with moderately reduced differential function, who were managed conservatively and showed improvement of function in 14 cases. It has been suggested that many neonatal kidneys with severe hydronephrosis are not obstructed despite major reductions in renal

\section{- Trimethoprim prophylaxis}

- Postnatal ultrasonography at 1 and 6 weeks*

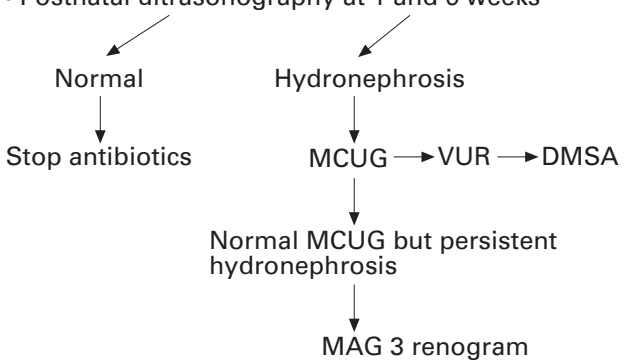

MCUG: micturating cystourethrography.

DMSA: ${ }^{99 \mathrm{~m}}$ Tc-labelled dimercaptosuccinic acid. MAG 3: ${ }^{99 \mathrm{~m}}$ Tc-labelled mercapto-acetyl triglycine. *Infants with severe biliteral hydronephrosis or evidence of bladder wall thickening should receive a renal ultrasound scan pre discharge because of the possibility of posterior urethral valves requiring urgent decompression.

Figure 1 Algorithm for the management of antenatally detected hydronephrosis (APPD renal pelvis $>4 \mathrm{~mm}$ ).

function. ${ }^{32}$ We have reserved the term PUJ obstruction for those infants who have evidence of renal pelvis dilatation with delayed drainage and relatively reduced renal function on MAG 3 studies. We advocate that infants with delayed drainage on MAG 3 without loss of function can be managed conservatively with serial dynamic renography and ultrasonography.

Finally, any potential abnormality detected during pregnancy is a source of enormous distress to parents and this is often compounded by communication difficulties between the relevant specialists. Counselling is difficult due to our limited understanding of the natural history of many of the problems; many anomalies, including vesico-ureteric reflux, may have no long term consequence and further studies are indicated to ascertain the importance of our findings.

With our present knowledge, we propose the following algorithm for the management of antenatally detected hydronephrosis (fig 1).

1 Helin I, Persson PH. Prenatal diagnosis of urinary tract abnormalities by ultrasound. Pediatrics $1986 ; 78: 879-83$ 2 Hudson JM, McNay MB, MacKenzie JR, Whittle MJ, disorders by ultrasonography. Lancet $1985 ; \mathbf{i} ; 621-3$.

3 Grieg JD, Young DG, Raine PA, et al. Value of antenatal diagnosis of abnormalities of urinary tract. BMF 1989;289:1417-19.

4 Thomas DFM. Fetal uropathy. Br 7 Urol 1990;66:225-31.

5 Lebowitz RL, Olbing H, Parkkulainen KV, et al: International system of radiographic grading of vesicoureteric national system of radiographic grading
reflux. Pediatr Radiol 1985;15:105-9.

6 Thomas DFM, Irvine HC, Arthur RJ. Prenatal diagnosis: Thow useful is it? Br f Urol 1985;57:784-7.

7 Livera LN, Brookfield DSK, Eggington JA, Hawnaur JM. Antenatal ultrasonography to detect fetal renal abnormalities: a prospective screening programme. BMF 1989;298:1421-3

8 Gunn TR, Mora JD, Pease P. Outcome after antenatal diagnosis of upper urinary tract dilatation by ultrasound. Arch Dis Child 1986;63:1240-3.

9 Madarikan BA, Hayward C, Roberts GM, Lari J. Clinical outcome of fetal uropathy. Arch Dis Child 1988;63:961-3.

10 Grignon A, Filion R, Filiatrault D, et al. Urinary tract dilatation in utero: classification and clinical applications. Radiology 1986;160: 645-7.

11 Arger PH, Coleman BG, Mintz, et al. Routine fetal genitourinary tract screening. Radiology 1985;156: 485-9.

12 Callan NA, Blakemore K, Park J, Sanders RC, Jeffs RD, Gearhart JP. Fetal genitourinary tract anomalies: evalua- 
tion, operative correction and follow-up. Obstet Gynaecol 1990;73:67-74

13 Blachar A, Blachar Y, Livne PH, Zurkowski L, Pelet D, Mogilner B. Clinical outcome and follow-up of prenatal hydronephrosis. Pediatr Nephrol 1994;8: 30-5.

14 Zerin JM, Ritchey ML, Chang ACH. Incidental vesicoureteral reflux in neonates with antenatally detected hydronephrosis and other renal abnormalities. Radiology 1993;187:157-60.

15 Marra G, Barbieri G, Moioli C, Assael BM, Caccamo ML. Mild fetal hydronephrosis indicating vesicoureteric reflux. Arch Dis Child 1994;70:F147-F50.

16 Grignon A, Filiatrault D, Homsy Y, Robitaille P, Filion R, Boutin $\mathrm{H}$, et al. Ureteropelvic junction stenosis: antenatal ultrasonographic diagnosis, postnatal investigation and follow-up. Radiology 1986;160: 649 .

17 Homsy YL, Koff SA. Problems in the diagnosis of obstruction in the neonate. In: Urologic surgery in neonates and tion in the neonate. In: Urologic surgery in neonates and

18 Johnson HW, Gleave M, Coleman GU, Nadel HR, Rafel J, Weckworth PF. Neonatal renomegaly. f Urol 1987; 138:1023.

19 Rolleston GL, Shannon FT, Uttley WLF. Relationship of infantile vesico-ureteric reflux to renal damage. $B M \mathcal{F}$ $1970 ; \mathbf{i}: 430-2$.

20 Ring E, Petritsch P, Riccabona M, Haim-Kuttnig M, Vilits $\mathrm{P}$, Rauchenwald $\mathrm{M}$, et al. Primary vesicoureteral reflux in infants with a dilated fetal urinary tract. Eur $\mathcal{F}$ Paediatr 1993;152:523-5.

21 Scott JES. Fetla ureteric reflux: A follow-up study. Br 7 Urol 1993;71: 481-3.

22 Huang FY, Tsai TC. Resolution of vesicoureteral reflux during medical management in children. Pediatr Nephrol 1995;6:715-18.
23 Crabbe DCG, Thomas DFM, Gordon AC, Irving HC, Arthur HC, Smith SEW. Use of $99 \mathrm{mTCDMSA}$ to show patterns of renal damage associated with prenatally detected vesicoureteral reflux. F Urol 1992;148:1229-31.

24 Burge DM, Griffiths MD, Malone PS, Atwell JD. Fetal vesicoureteral reflux: Outcome following conservative postnatal management. F Urol 1992;148:1743-5.

25 Elder JS. Importance of antenatal diagnosis of vesicoureteral reflux.f Urol 1992;148: 1750-4.

26 Clarke NW, Gough DCS, Cohen SJ. Neonatal urological ultrasound: diagnostic inaccuracies and pitfalls. Arch Dis Child 1989;64: 578-80.

27 Hoddick WK, Filly RA, Mahoney BS, Callen PW. Minimal fetal renal pyelectasis. F Ultrasound Med 1985;4: 85-9.

28 King LR, Coughlin PWF, Bloch EC, Bowie JD, Ansong K, Hanna MK. The case for immediate pyeloplasty in the neonate with ureteropelvic junction obstruction. F Urol 1984;132: 75 .

29 Guys JJ, Borella F, Monfort G. Ureteropelvic junction obstruction: prenatal diagnosis and neonatal surgery in 47 cases. F Pediatr Surg 1988;23:156.

30 Dowling KJ, Harmon EP, Ortenberg J, Polanco E, Evans BB. Ureteropelvic junction obstruction: the effect of pyeloplasty on renal function. F Urol 1988;140:1227-30.

31 Ransley PG, Dhillon HK, Gordon I, Duffy PG, Dillon MJ, Barratt TM. The postnatal management of hydronephrosis diagnosed by prenatal ultrasound. F Urol 1988;144: 584-97.

32 Koff SA, Campbell K. Nonoperative management of unilateral neonatal hydronephrosis. F Urol 1992;148:525-31. 